\title{
Measurements of Soil Surface Roughness During the Fourth Microwave Water and Energy Balance Experiment: April 18 through June 13, 2005 ${ }^{1}$
}

Mi-young Jang, Kai-Jen Calvin Tien, Joaquin Casanova, and Jasmeet Judge ${ }^{2}$

1. This document is Circular 1483, one of a series of the Agricultural and Biological Engineering Department, Florida Cooperative Extension Service, Institute of Food and Agricultural Sciences, University of Florida. First published November 2005. Please visit the EDIS Web site at http://edis.ifas.ufl.edu.

2. Mi-young Jang and Kai-Jen Tien are Graduate Research Assistants; Joaquin Casanova is an Undergraduate Research Assistant; and Jasmeet Judge is an Assistant Professor and Director of Center for Remote Sensing (email: jasmeet@ufl.edu). All authors are affiliated with the Agricultural and Biological Engineering Department, Institute of Food and Agricultural Sciences, University of Florida, Gainesville, 32611.

The Institute of Food and Agricultural Sciences (IFAS) is an Equal Opportunity Institution authorized to provide research, educational information and other services only to individuals and institutions that function with non-discrimination with respect to race, creed, color, religion, age, disability, sex, sexual orientation, marital status, national origin, political opinions or affiliations. U.S. Department of Agriculture, Cooperative Extension Service, University of Florida, IFAS, Florida A. \& M. University Cooperative Extension Program, and Boards of County Commissioners Cooperating. Larry Arrington, Dean 


\section{TABLE OF CONTENTS}

1. INTRODUCTION

2. SOIL SURFACE STATISTICS

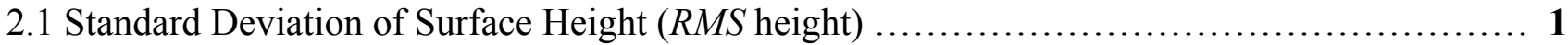

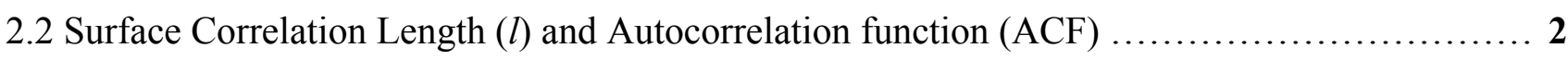

3. SURFACE ROUGHNESS MEASUREMENTS ........................................ 2

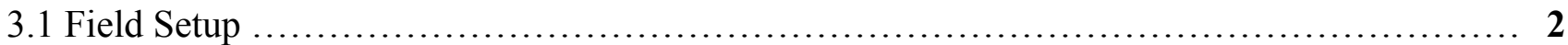

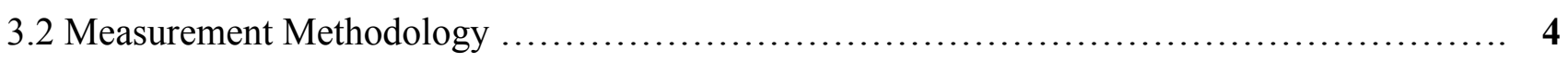

3.3 Roughness Parameter Calculation $\quad \ldots \ldots \ldots \ldots \ldots \ldots \ldots \ldots \ldots \ldots \ldots \ldots \ldots \ldots \ldots \ldots \ldots \ldots \ldots \ldots$

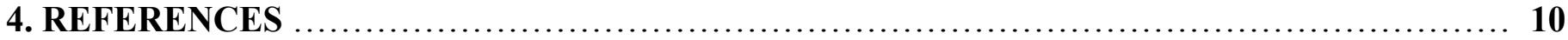

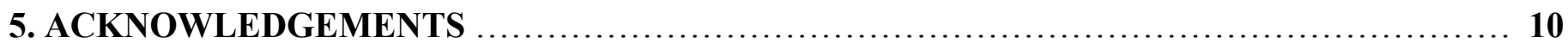

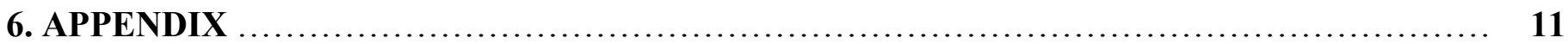

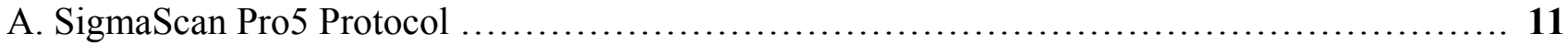

B. EXCEL Spreadsheet for Roughness Calculations .................................... 15 


\section{INTRODUCTION}

Passive microwave signatures have been used to retrieve geophysical parameters, such as soil temperature [Njoku and Li, 1999], moisture [Jackson et al., 1995], and surface roughness [Wegmüller and Mätzler, 1999]. One of the challenges in the parameter retrieval is the effect of soil surface roughness on the microwave emission. We conducted soil surface roughness measurements as part of our fourth Microwave Water and Energy Balance Experiment (MicroWEX-4) to understand the effects of surface roughness on microwave signatures at $6.7 \mathrm{GHz}(\lambda=4.48 \mathrm{~cm})$. The dataset will also be used to develop and validate surface roughness models. In this report, we summarize briefly the theoretical background of surface roughness characteristics and discuss methodology and results of the roughness experiments.

\section{SOIL SURFACE STATISTICS}

Soil surface can be characterized mainly by three parameters; the standard deviation of surface height (rms height, $\sigma$ ), the surface correlation length $(l)$, and the auto correlation function (ACF). The rms height describes random surface characteristics, while the correlation length and the correlation function describe periodicity of the surface (Ulaby et al., 1982). Figures 1(a) and (b) show random height variations superimposed on either a periodic or a flat surface.

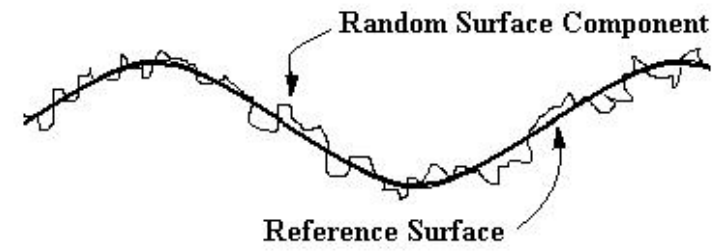

(a)

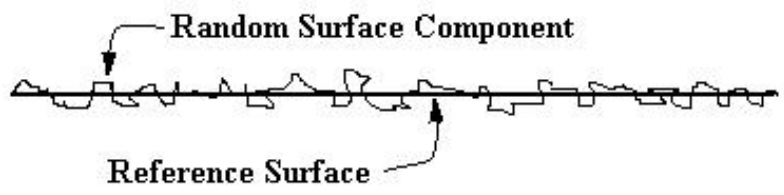

(b)

Figure 1. Random height variations superimposed on a (a) periodic surface (b) flat surface.

\subsection{Standard Deviation of Surface Height (RMS height)}

In terms of the mean surface height $(\bar{z})$ and the second moment $\left(\overline{z^{2}}\right)$, the rms height, $\sigma$, is then given by

$$
\sigma=\left(\overline{z^{2}}-\bar{z}^{2}\right)^{1 / 2}
$$

For a one-dimensional surface profile, $\sigma$ is computed by digitizing the profile into discrete values, $z_{i}\left(x_{i}\right)$, at an appropriate horizontal spacing, $\Delta x$. If the height variation, $\Delta z$, corresponding to a $\Delta x$ is much smaller than the wavelength, $\lambda$, of the incident wave, the variation will have no effect on the reflection from the surface of $\Delta x$. Typically, $\Delta x \leq 0.1 \lambda$. The standard deviation $\sigma$ for the discrete one-dimensional case is given by,

$$
\sigma=\left[\frac{1}{N}\left(\sum_{i=1}^{N}\left(z_{i}\right)^{2}-N(\bar{z})^{2}\right)\right]^{1 / 2}
$$

where $N$ is the number of samples and 


$$
\bar{z}=\frac{1}{N} \sum_{i=1}^{N} z_{i},
$$

\subsection{Surface Correlation Length $(l)$ and Autocorrelation Function (ACF)}

A surface autocorrelation curve is used to determine the correlation length and the autocorrelation function (ACF). The autocorrelation is a measure of the similarity between the height, $z(x)$, at a point $x$ and the height, $z\left(x+x^{\prime}\right)$, at a point $x+x^{\prime}$. The normalized ACF, $\rho(x)$, for a one-dimensional surface profile of length, $L$, is defined as,

$$
\rho\left(x^{\prime}\right)=\frac{\int_{-L_{x} / 2}^{L_{x} / 2} z(x) z\left(x+x^{\prime}\right) d x}{\int_{-L_{x} / 2}^{L_{x} / 2} z^{2}(x) d x}
$$

For a discrete case, $\rho\left(x^{\prime}\right)$ for $x^{\prime}=(j-1) \Delta x$, where $j$ is an integer $\geq 1$, is given by

$$
\rho\left(x^{\prime}\right)=\frac{\sum_{i=1}^{N+1-j} z_{i} z_{j+i-1}}{\sum_{i=1}^{N} z_{i}{ }^{2}} .
$$

The correlation length, $l$, is the displacement, $x$, for which $\rho\left(x^{\prime}\right)=1 / e$ :

$$
\rho(l)=1 / e
$$

It is used to fit a theoretical correlation function, such as exponential or gaussian, to the measured autocorrelation curve by optimizing the power coefficient $(n)$. The ACF is mathematically represented by,

$$
\rho\left(x^{\prime}\right)=\exp \left(x^{\prime} / l\right)^{n}
$$

where $n$ describes the correlation function. For example, $n=1$ for an exponential ACF and $n=2$ for a gaussian ACF.

\section{Surface Roughness Measurements}

\subsection{Field Setup}

Soil surface roughness measurements were conducted by the Center for Remote Sensing, Agricultural and Biological Engineering Department, at the Plant Science Research and Education Unit (PSREU), IFAS, Citra, FL, as the part of the Fourth Microwave Water and Energy Balance Experiment (MicroWEX-4) [Casanova et al., 2005]. Roughness was measured weekly from April 18 to June 13 in 2005, during the corn-growing season. Figure 2 shows the field site and the three regions of the field used for roughness measurements: The eastern region that was very rough, the western region that was very smooth, and the radiometer footprint area that was of intermediate roughness. The figure also shows four profile directions used for the measurements: Parallel and perpendicular to the row direction and to the radiometer look direction. Table 1 shows the sampling dates and events of the measurements. A total of 62 soil surface profiles were measured during the experiment. 


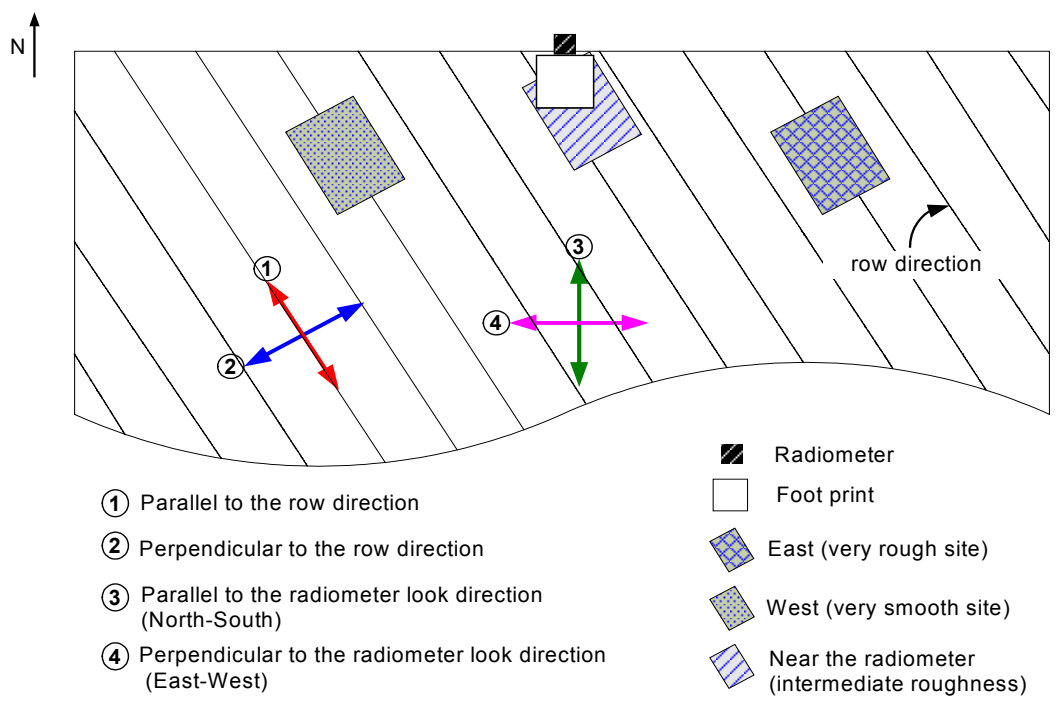

Figure 2. Three sites and four profile directions for the soil surface roughness measurements.

Table 1. Schedule of surface roughness measurements

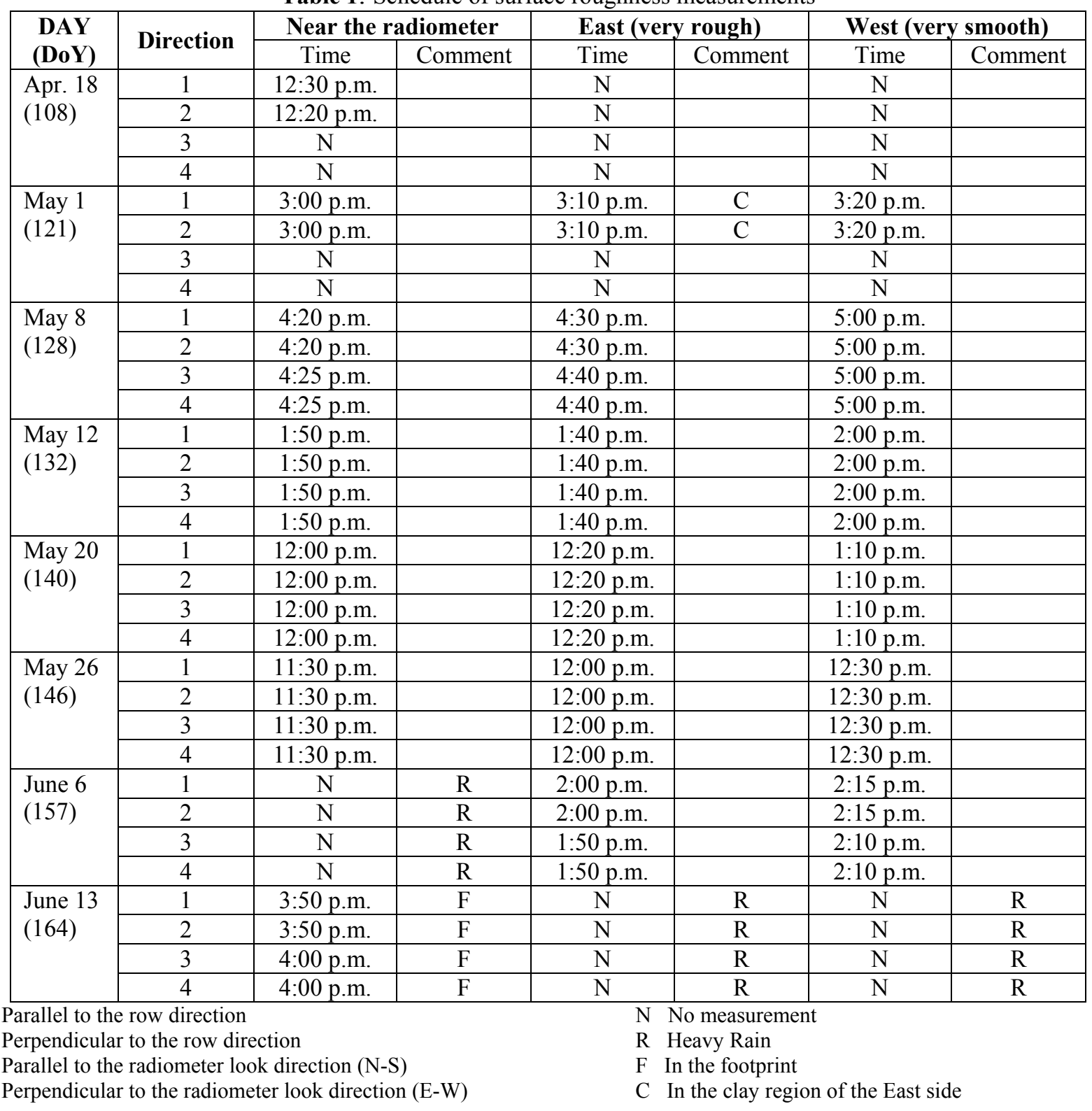




\subsection{Measurement Methodology}

Soil surface height was measured using a $2.14 \mathrm{~m} \mathrm{X} 0.9$ m metal mesh-board, as shown in Figure 3. The board was marked at intervals of $2 \mathrm{~cm}$ for the accurate sampling. A picture was taken using a digital camera and scanned. Each picture was digitized using the SigmaScan Pro5 software, with distance on the $x$-axis and height on the $y$-axis. The digitization followed one of the two methods described by [Jackson et al., 2004]. We took a height measurement at every point where the slope of the surface changed or at least at every 1$\mathrm{cm}$ interval. Thus, for our $2.14 \mathrm{~m}$ long mesh-board, each digitized picture yields 214 data points, provided there were no missed sampling point. Detailed protocol of using the Sigmascan Pro5 software is described in Appendix A.

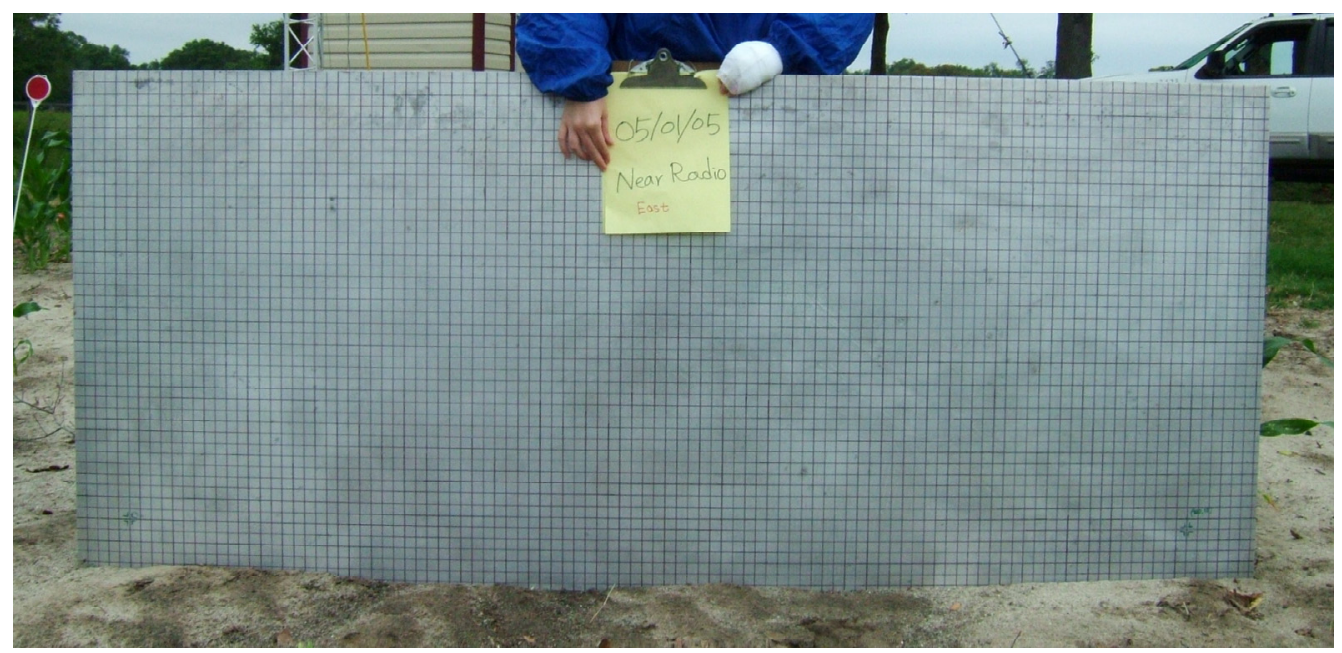

Figure 3. A 2.14 m long metal mesh-board

\subsection{Roughness Parameter Calculation}

The roughness parameters, $\sigma, l$, and ACF, were calculated using an EXCEL spread sheet, enabled with Marcos, as shown in Appendix B (Dr. M. Cosh, personal communication, 2005). The program interpolated the digitized surface profiles and computed the roughness parameters. It also corrected for the slope of the roughness board using a 'least square' fit and calculated an adjusted $\sigma$. For our case, with, we selected. The program was applied to our 64 profiles, using $\Delta x=1 \mathrm{~mm}$ (for our case, $\lambda=4.5 \mathrm{~cm}$ ). The interpolated soil surface profiles are shown in Figure 4 (a-c). The $\sigma$ and $l$ are shown in Table 2. Figures 5 (a-f) show the measured ACFs compared with the Gaussian and the Exponential correlation functions. 

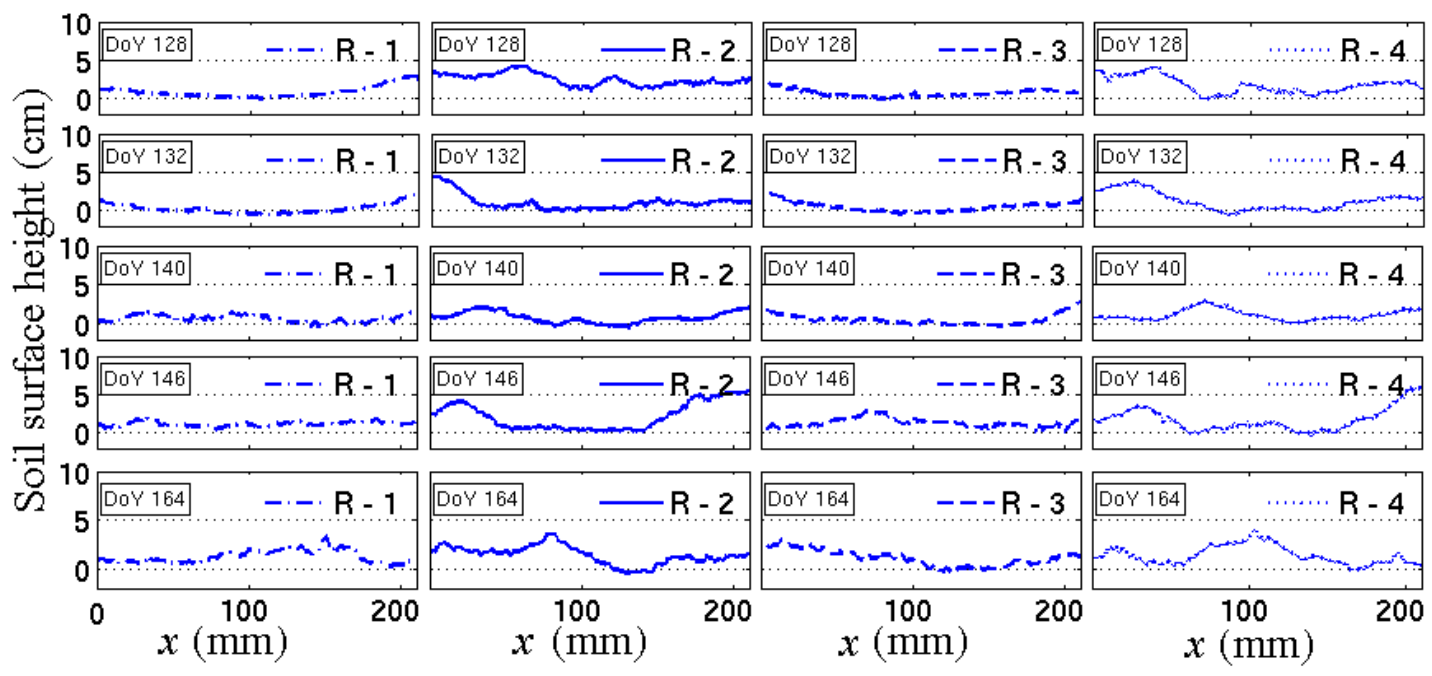

(a)
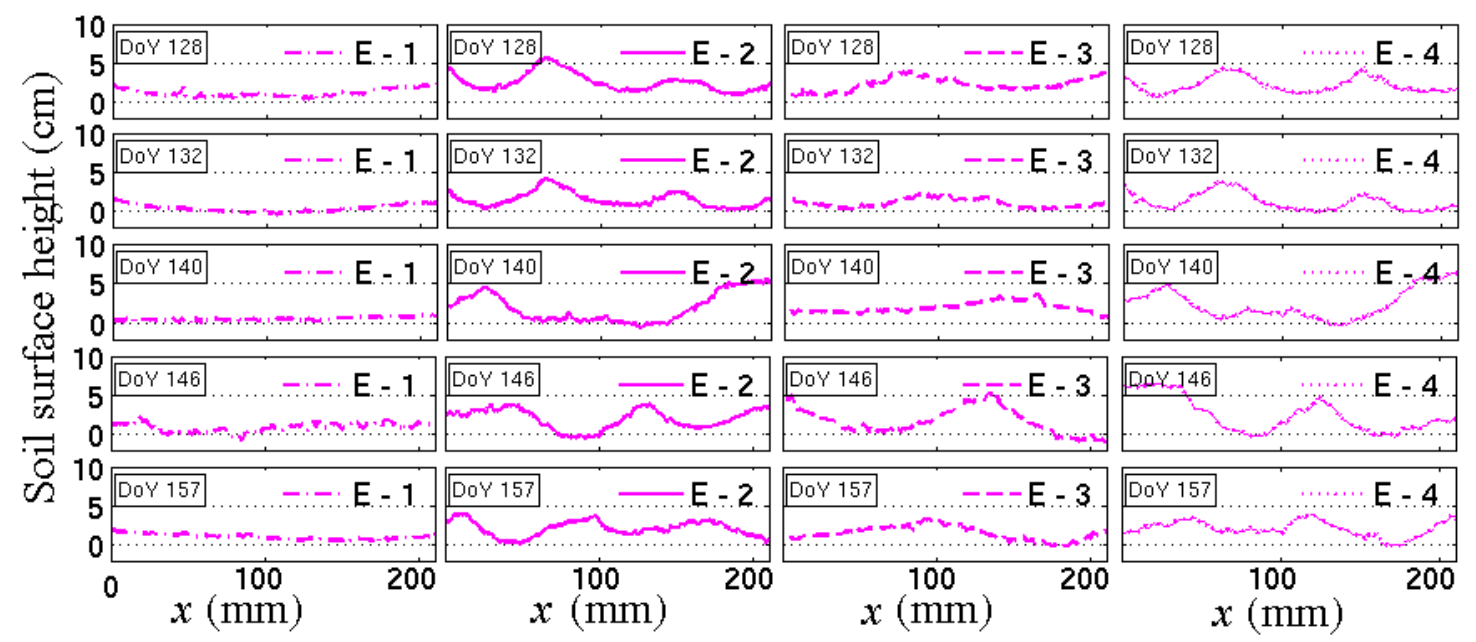

(b)
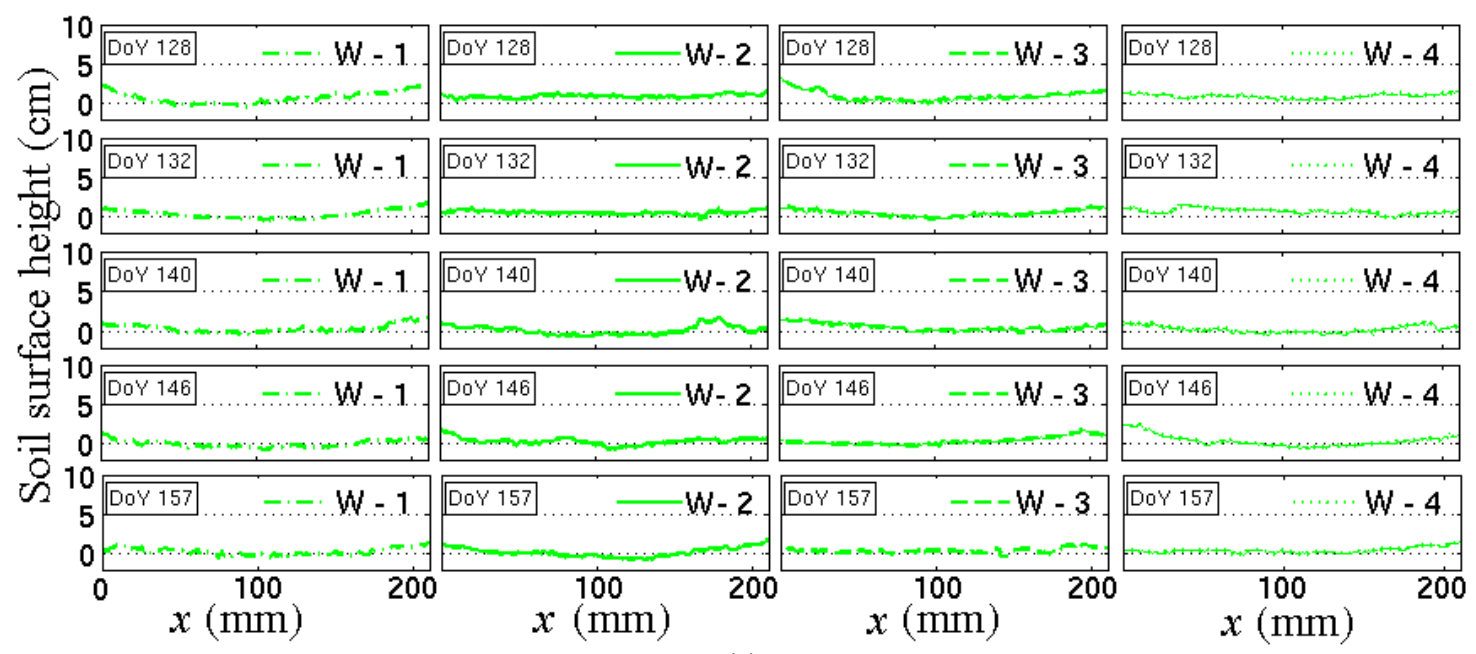

(c)

Figure 4. Digitized soil surface profiles for (a) near the radiometer footprint (R), (b) at the East site (E), and (c) the West site (W). 1 to 4 represent parallel and perpendicular to the row direction and the radiometer look direction, respectively. 
Table 2. Measured soil surface roughness parameters

\begin{tabular}{|c|c|c|c|c|c|c|c|}
\hline \multirow{2}{*}{$\begin{array}{c}\text { DAY } \\
\text { (DoY) }\end{array}$} & \multirow[b]{2}{*}{ Direction } & \multicolumn{2}{|c|}{ Near the radiometer } & \multicolumn{2}{|c|}{ East (very rough) } & \multicolumn{2}{|c|}{ West (very smooth) } \\
\hline & & $\begin{array}{l}\text { rms height } \\
(\mathrm{mm})\end{array}$ & $\begin{array}{c}\text { Correlation } \\
\text { length }(\mathrm{mm})\end{array}$ & $\begin{array}{l}\text { rms height } \\
(\mathrm{mm})\end{array}$ & $\begin{array}{c}\text { Correlation } \\
\text { length }(\mathrm{mm})\end{array}$ & $\begin{array}{l}\text { rms height } \\
(\mathrm{mm})\end{array}$ & $\begin{array}{l}\text { Correlation } \\
\text { length }(\mathrm{mm})\end{array}$ \\
\hline \multirow{4}{*}{$\begin{array}{l}\text { Apr. } 18 \\
(108)\end{array}$} & 1 & 7.9 & 92.0 & - & - & - & - \\
\hline & 2 & 16.4 & 147.0 & - & - & - & - \\
\hline & 3 & - & - & - & - & - & - \\
\hline & 4 & - & - & - & - & - & - \\
\hline \multirow{4}{*}{$\begin{array}{l}\text { May } 1 \\
(121)\end{array}$} & 1 & & & & & & \\
\hline & 2 & & & & & & \\
\hline & 3 & - & - & - & - & - & - \\
\hline & 4 & - & - & - & - & - & - \\
\hline \multirow{4}{*}{$\begin{array}{l}\text { May } 8 \\
(128)\end{array}$} & 1 & 7.0 & 265.1 & 4.8 & 246.5 & 7.0 & 275.6 \\
\hline & 2 & 7.2 & 205.0 & 11.2 & 180.5 & 2.4 & 73.5 \\
\hline & 3 & 4.8 & 204.8 & 8.4 & 219.2 & 6.2 & 204.9 \\
\hline & 4 & 10.2 & 218.7 & 9.7 & 149.3 & 3.0 & 140.1 \\
\hline \multirow{4}{*}{$\begin{array}{l}\text { May } 12 \\
(132)\end{array}$} & 1 & 6.1 & 226.7 & 4.6 & 275.7 & 5.2 & 291.1 \\
\hline & 2 & 9.6 & 145.4 & 9.4 & 161.6 & 2.2 & 88.0 \\
\hline & 3 & 6.2 & 268.7 & 5.5 & 230.5 & 3.9 & 252.8 \\
\hline & 4 & 11.3 & 282.4 & 10.4 & 169.4 & 3.3 & 142.7 \\
\hline \multirow{4}{*}{$\begin{array}{l}\text { May } 20 \\
(140)\end{array}$} & 1 & 4.5 & 147.0 & 1.9 & 307.6 & 4.9 & 204.4 \\
\hline & 2 & 7.1 & 212.4 & 18.3 & 261.0 & 5.5 & 212.8 \\
\hline & 3 & 6.6 & 155.9 & 6.3 & 281.6 & 3.9 & 294.9 \\
\hline & 4 & 6.9 & 190.6 & 18.5 & 233.0 & 4.1 & 240.1 \\
\hline \multirow{4}{*}{$\begin{array}{l}\text { May } 26 \\
(146)\end{array}$} & 1 & 3.2 & 79.9 & 5.4 & 160.2 & 4.5 & 200.5 \\
\hline & 2 & 17.4 & 285.8 & 12.8 & 175.0 & 4.5 & 122.0 \\
\hline & 3 & 6.0 & 195.8 & 16.6 & 223.6 & 4.5 & 329.7 \\
\hline & 4 & 15.4 & 189.7 & 19.9 & 228.9 & 7.1 & 237.3 \\
\hline \multirow{4}{*}{$\begin{array}{l}\text { June } 6 \\
(157)\end{array}$} & 1 & - & - & 3.1 & 355.2 & 4.4 & 218.6 \\
\hline & 2 & - & - & 9.6 & 131.8 & 5.6 & 275.7 \\
\hline & 3 & - & - & 8.7 & 309.2 & 2.8 & 94.2 \\
\hline & 4 & - & - & 9.7 & 149.8 & 3.2 & 244.8 \\
\hline \multirow{4}{*}{$\begin{array}{l}\text { June } 13 \\
(164)\end{array}$} & 1 & 6.6 & 231.1 & - & - & - & - \\
\hline & 2 & 8.9 & 237.2 & - & - & - & - \\
\hline & 3 & 7.5 & 366.5 & - & - & - & - \\
\hline & 4 & 9.2 & 225.7 & - & - & - & - \\
\hline
\end{tabular}

1. Parallel to the row direction

2. Perpendicular to the row direction
3. Parallel to the radiometer look direction (N-S)

4. Perpendicular to the radiometer look direction (E-W) 

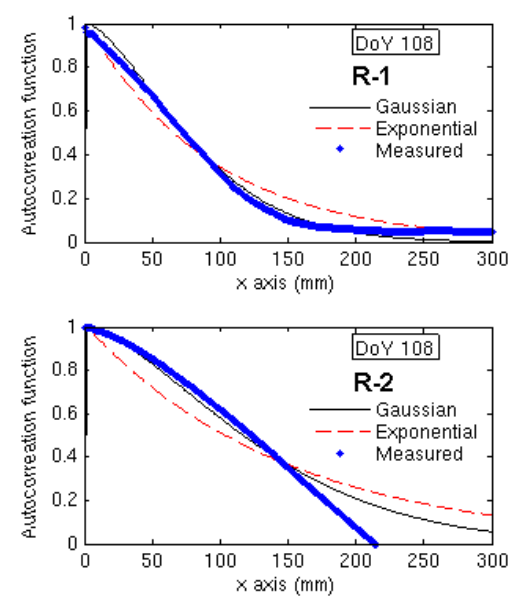

(a)
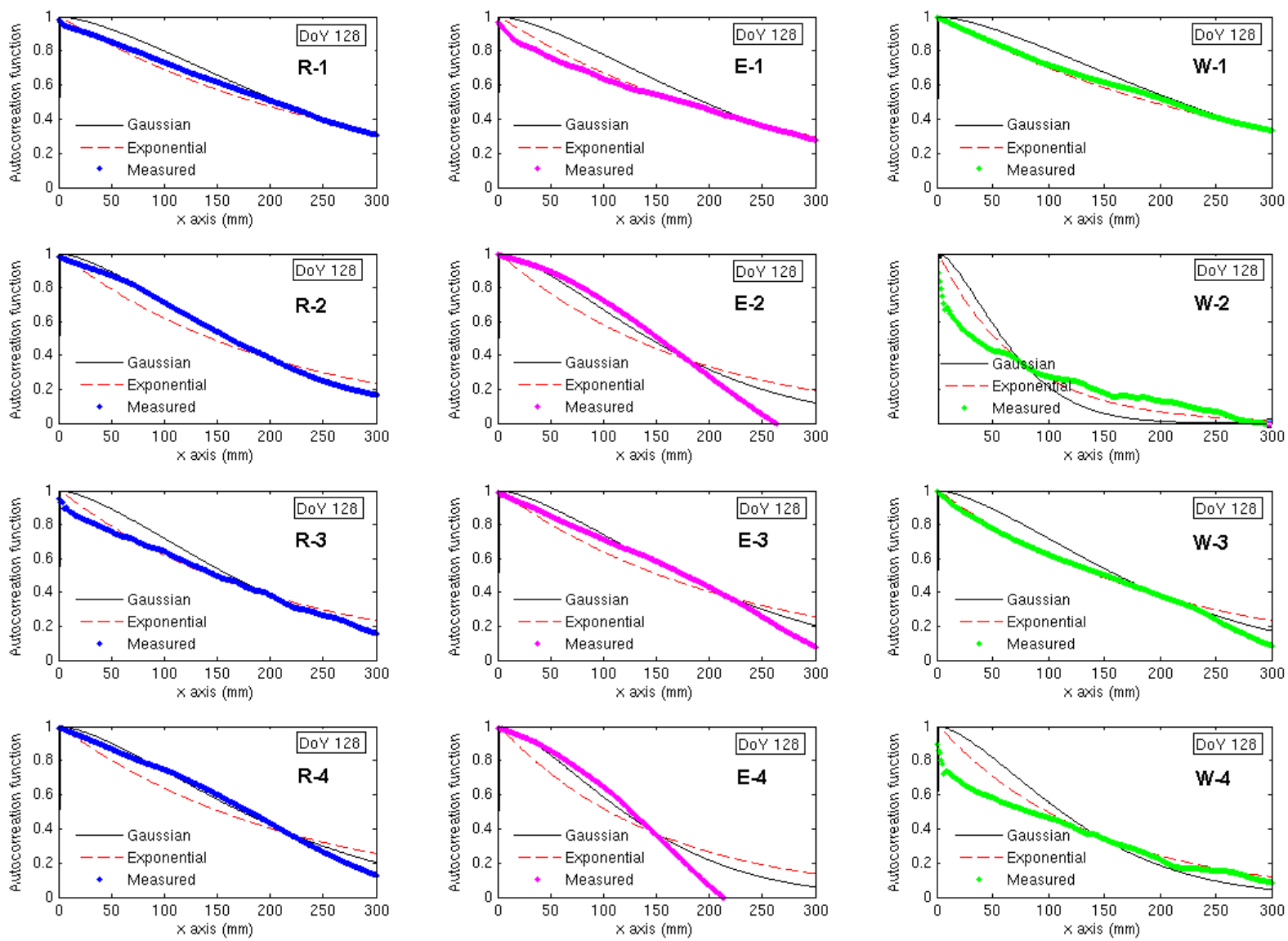

(b)

Figure 5. Measured ACF compared with Gaussian and Exponential (a) April 18 (DOY 108), (b) May 8 (DOY 128). R, E and W represent near the radiometer, at the East site and the West site, respectively; and 1 to 4 represent parallel and perpendicular to the row direction and the radiometer look direction, respectively. 

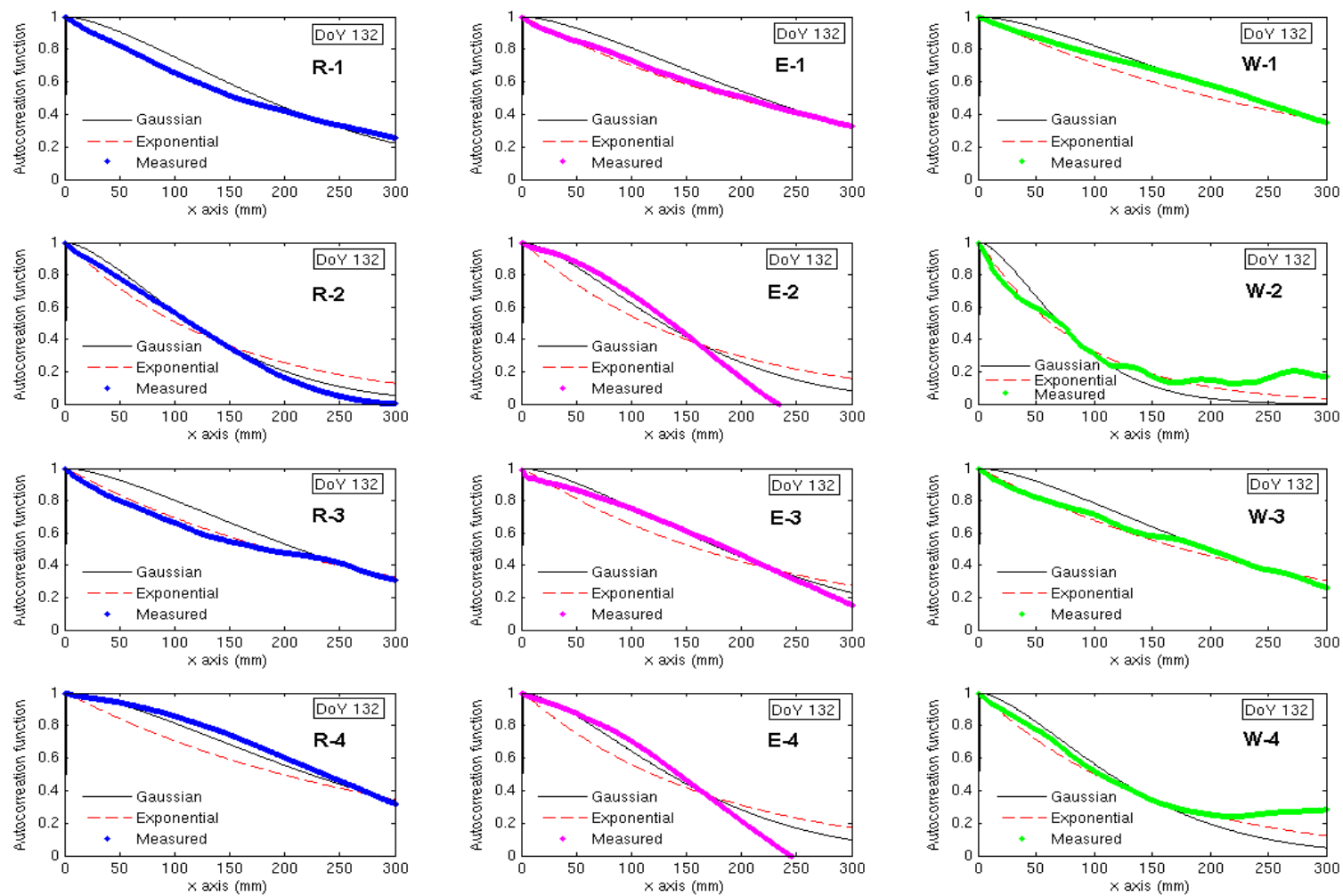

(c)
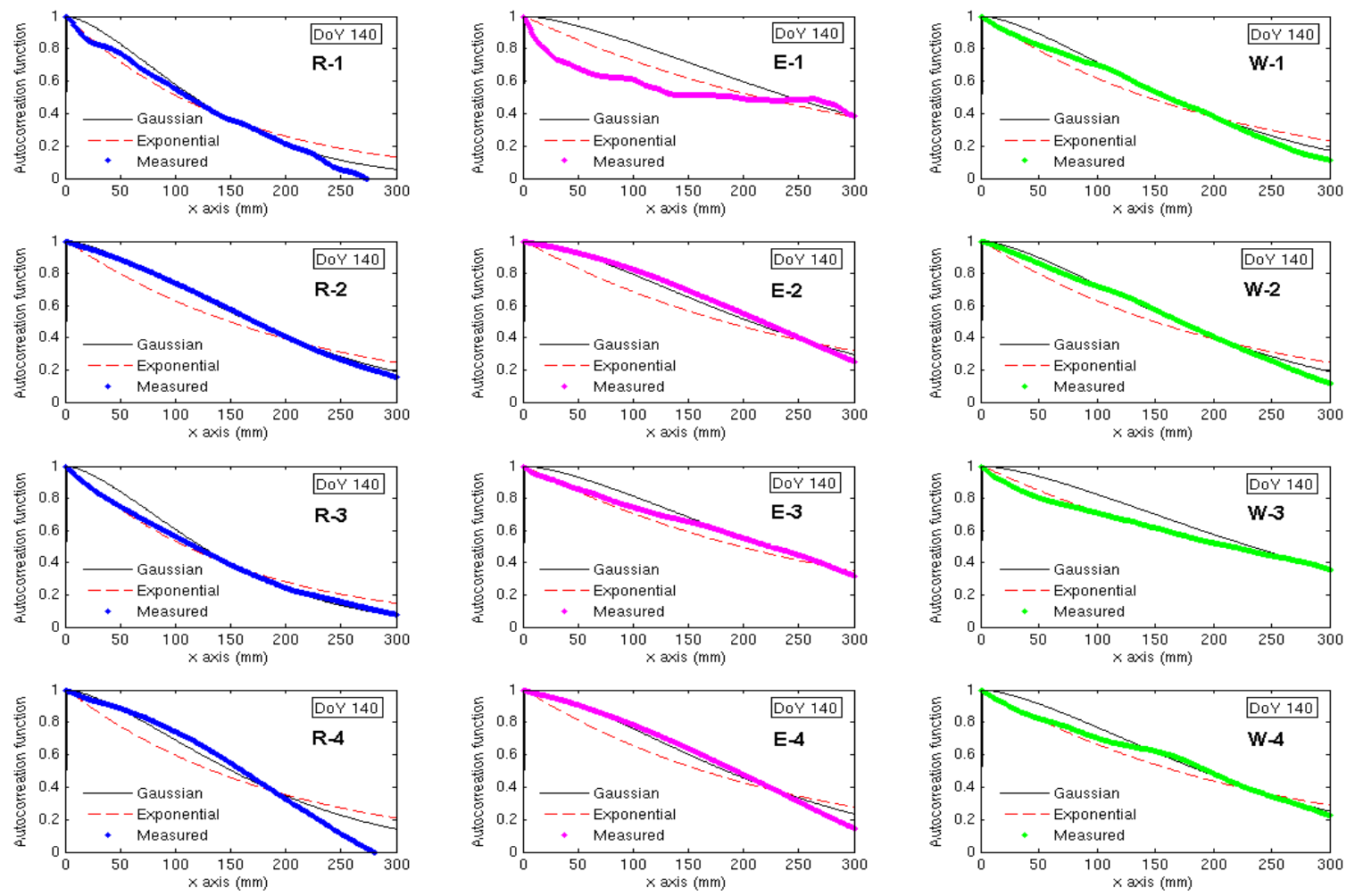

(d)

Figure 5 (contd). (c) May 12 (DOY 132) (d) May 20 (DOY 140). 

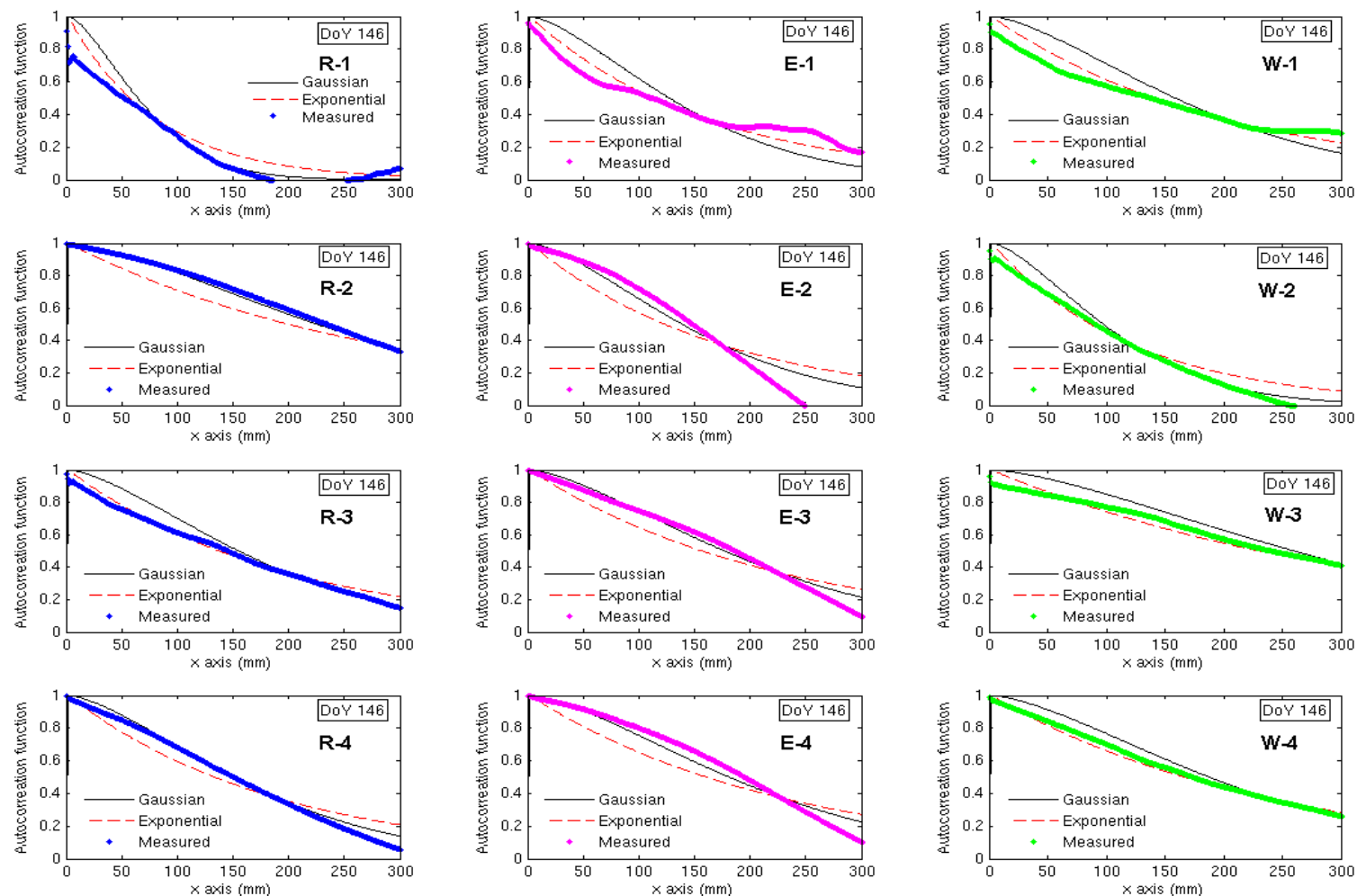

(e)
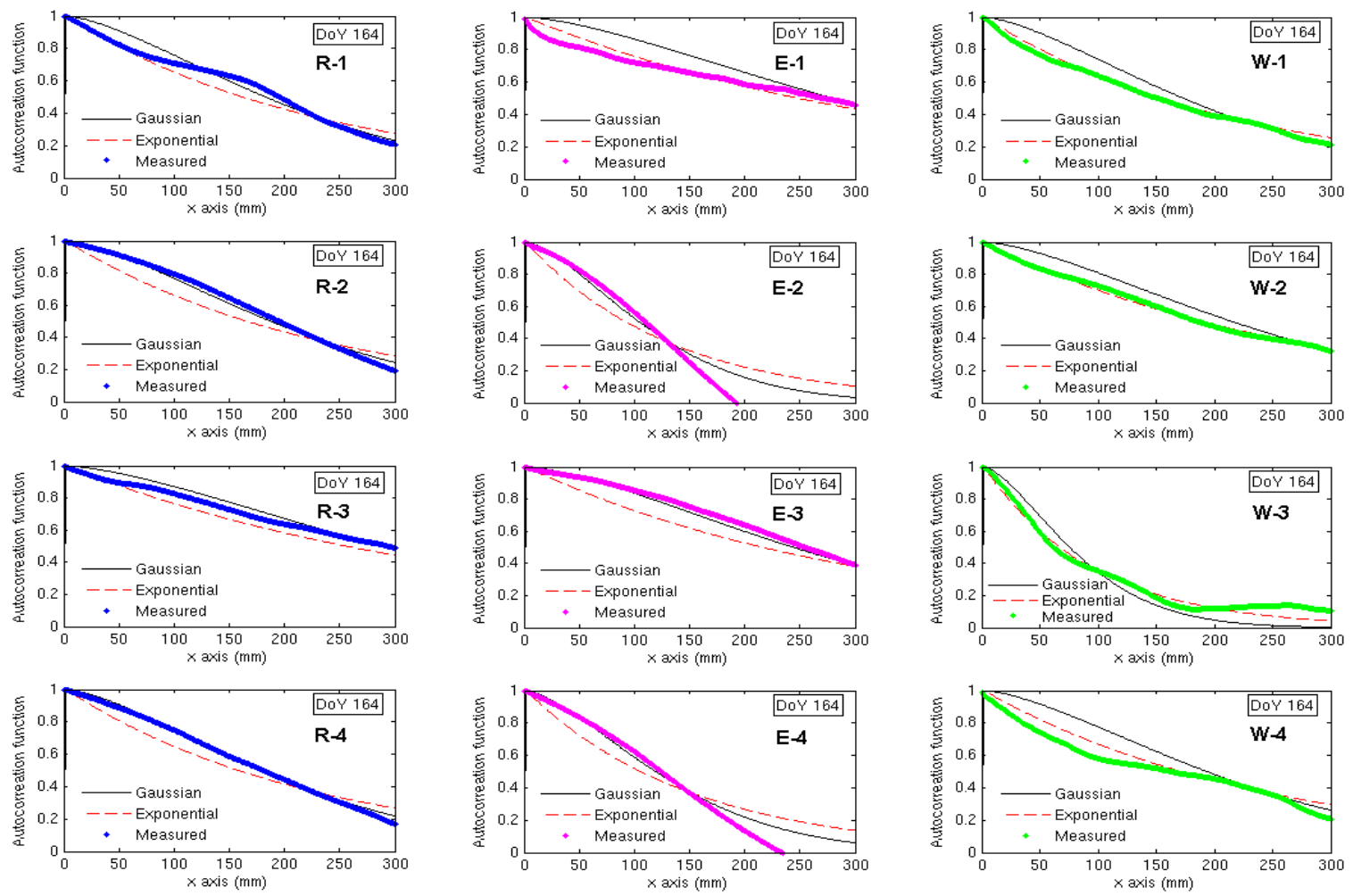

(f)

Figure 5 (contd). (e) May 26 (DOY 146) and (f) June 13 (DOY 164). 


\section{REFERENCES}

J.J. Casanova, T. Y. Lin, J. Judge, K. J. C. Tien, M. Y. Jang, O. Lanni, and L. Miller, The Fourth Microwave Water and Energy balance Experiment (MicroWEX-4): from March 10 - June 14, 2005, Circular Number 1482, Center for Remote Sensing, University of Florida, Available at UF/IFAS, EDIS Web site, http://edis.ifas.ufl.edu/AE362, 2005.

T.J. Jackson, D.E. LeVine, C.T. Swift, T. J. Schmugge, and F.R. Schiebe, Large area mapping of soil moisture using the ESTAR passive microwave radiometer in Washita '92, Remote Sens. Environ, 53, pp. 27-37, 1995.

T.J. Jackson and L. McKee, Soil roughness measurements in the walnut creek watershed during SMEX02, Ancillary data available at http://nsidc.org/data/docs/daac/nsidc0204_smex ancillary.gd.html, 2004.

E.G. Njoku and L. Li, Retrieval of land surface parameters using passive microwave measurements at 6-18 GHz, IEEE Trans. Geosci. Remote Sensing, v37, pp. 9-93, 1999.

F.T. Ulaby, R. K. Moore, and A. K. Fung, Microwave Remote Sensing, Active and Passive, Vol. II, Artech House, Dedham, MA, 1982.

U. Wegmüller and C. Mätzler, Rough bare soil reflectivity model, IEEE Trans. Geosci. Remote Sensing, 37, pp. 1391-1395, 1999.

\section{ACKNOWLEDGEMENTS}

This research was supported by the NASA-New Investigator Program Grant \#0005065. The authors would like to thank Dr. Michael Cosh (USDA) for assisting with the digitization protocol and calculation of roughness parameters; and Mr. Orlando Lanni for his help in constructing the mesh-board. 


\section{APPENDIX}

\section{A. SigmaScan Pro5 Software Protocol}

1) Start SigmaScan Pro 5

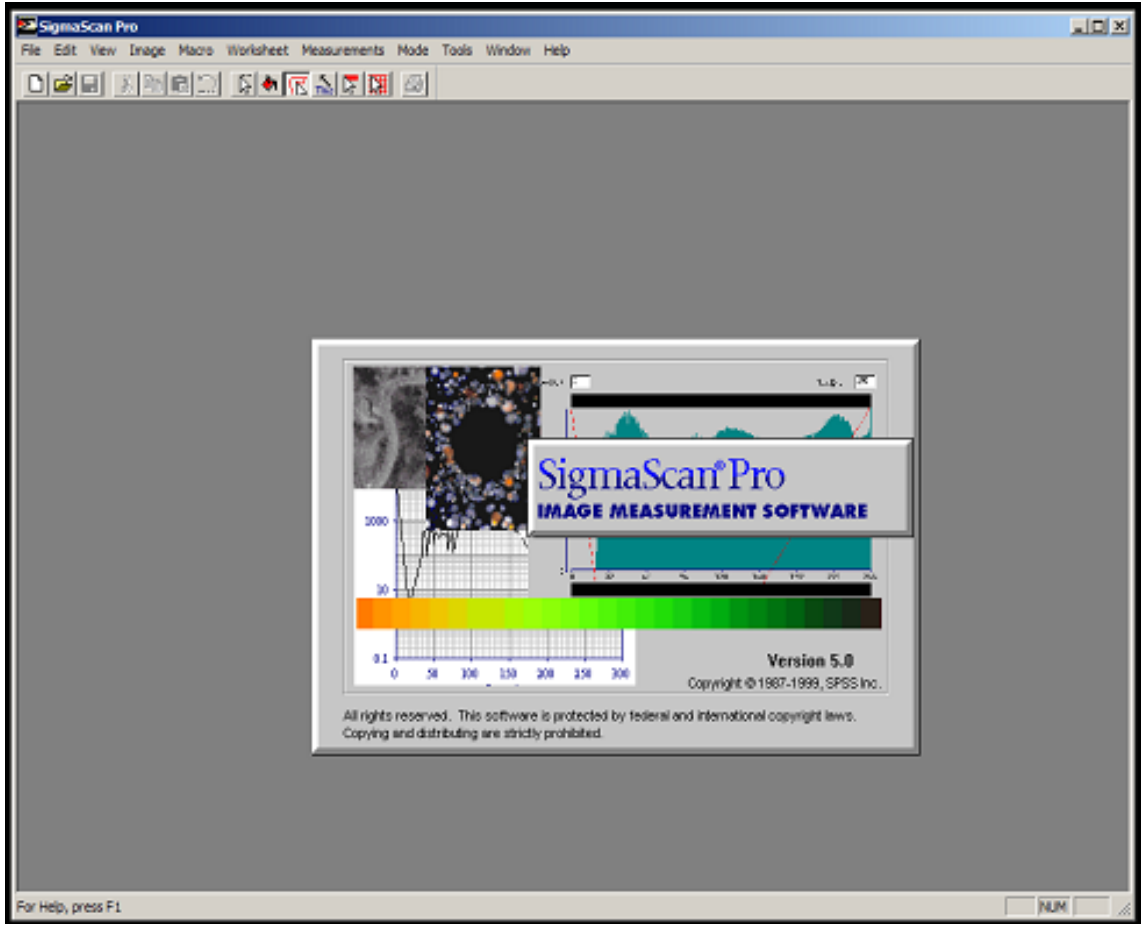

2) Select File $>$ Open $>$ Image. Click on the image to be processed and then click Open. Click View $>$ Zoom Out to achieve the proper image display on the window.

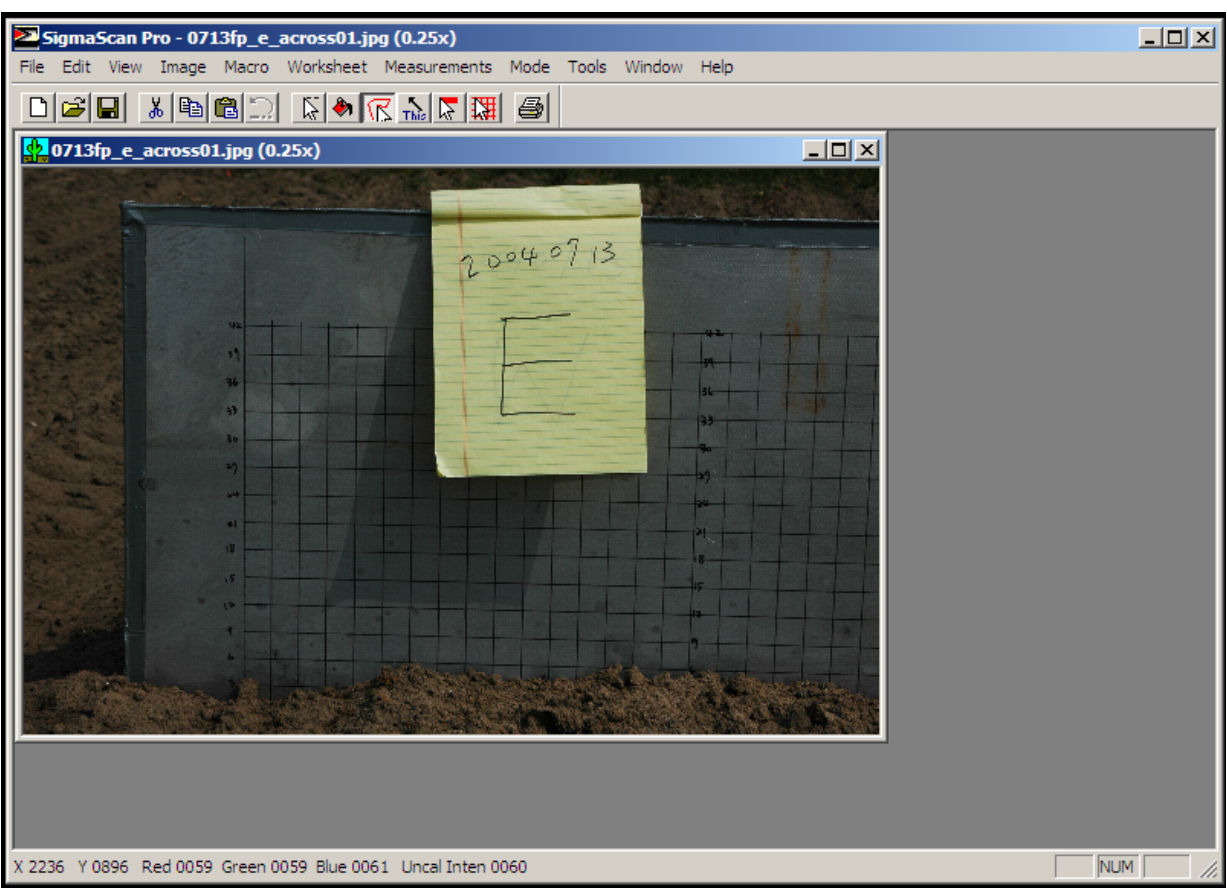


3) Select Image $>$ Calibrate $>$ Distance and Area and click on 3 Point-Calibration. On the Uncalibrated [X,Y] are the coordinates of the original image coordinates, whose default values are $[0,0],[100,0]$, and $[100,100]$ for point 1,2 , and 3 respectively. On the Calibrated $[\mathrm{X}, \mathrm{Y}]$ are the coordinates of the image based on the grid point coordinates, whose default values are $[0,0],[100,0]$, and $[100,100]$ for point 1,2 , and 3 , respectively.

4) Use the mouse pointer to select the points at the (1) far left, (2) far right, and (3) center of the grid board coordinates in the image (as shown in the figure). The coordinates in the Uncalibrated [X,Y] will change to the points that are selected. Type in coordinates of the three selected points corresponding to the grid point coordinates and click $\mathrm{OK}$.

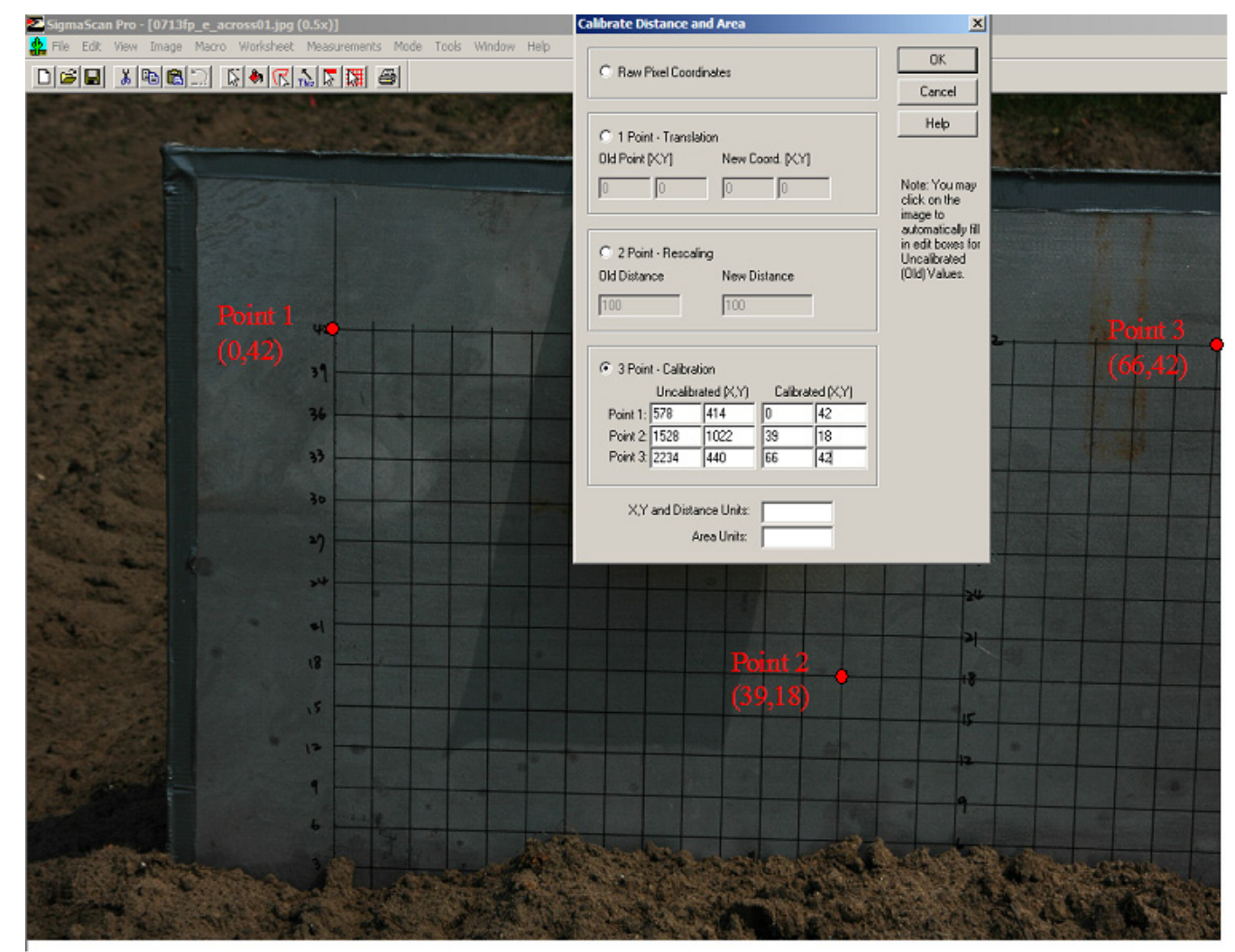


5) Select Measurement $>$ Settings, in Measurements window select only the last two options $x$ and $y$ of measurement type Point as Column A and B and click OK.

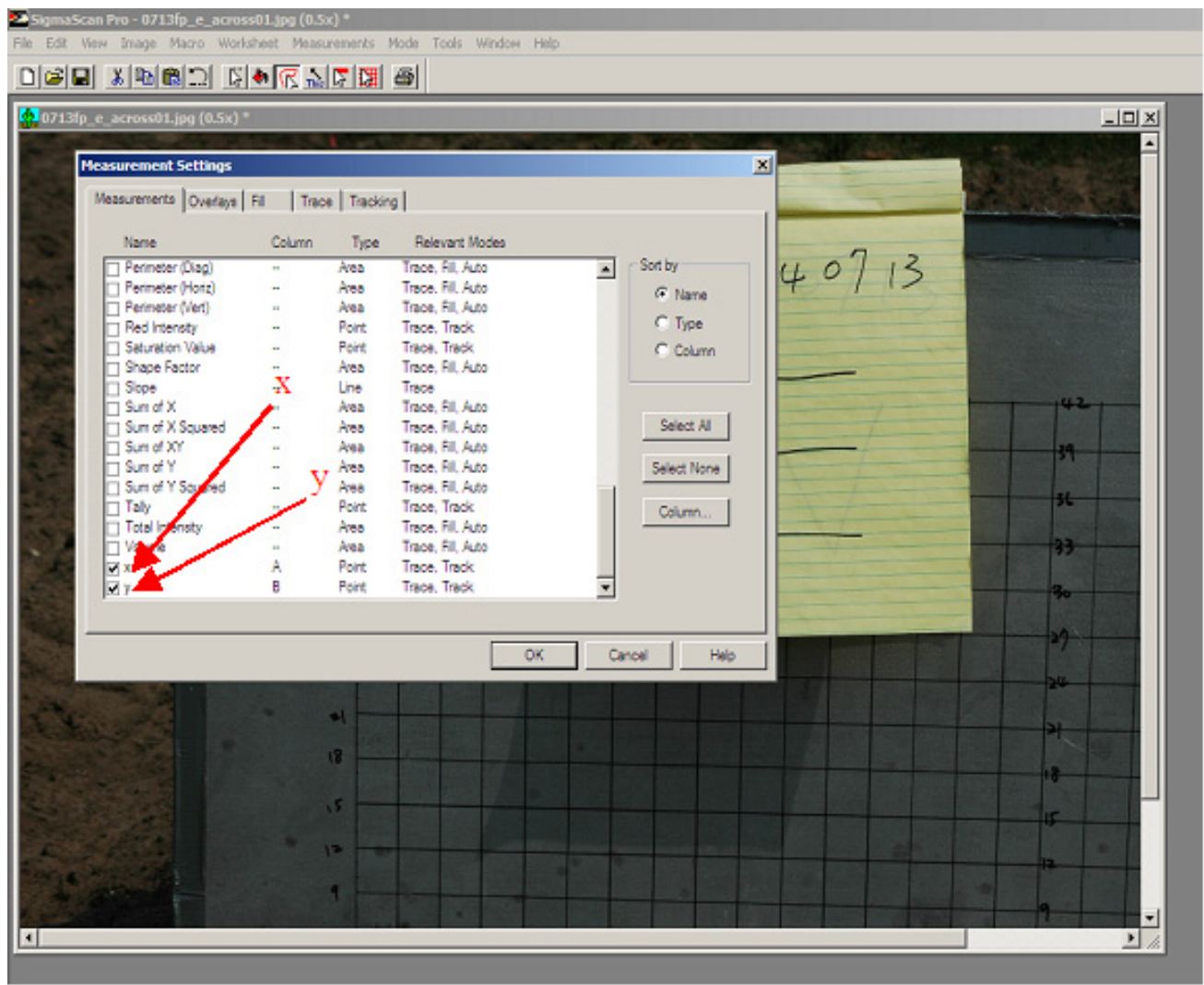

6) Select Mode>Trace Measurement Mode

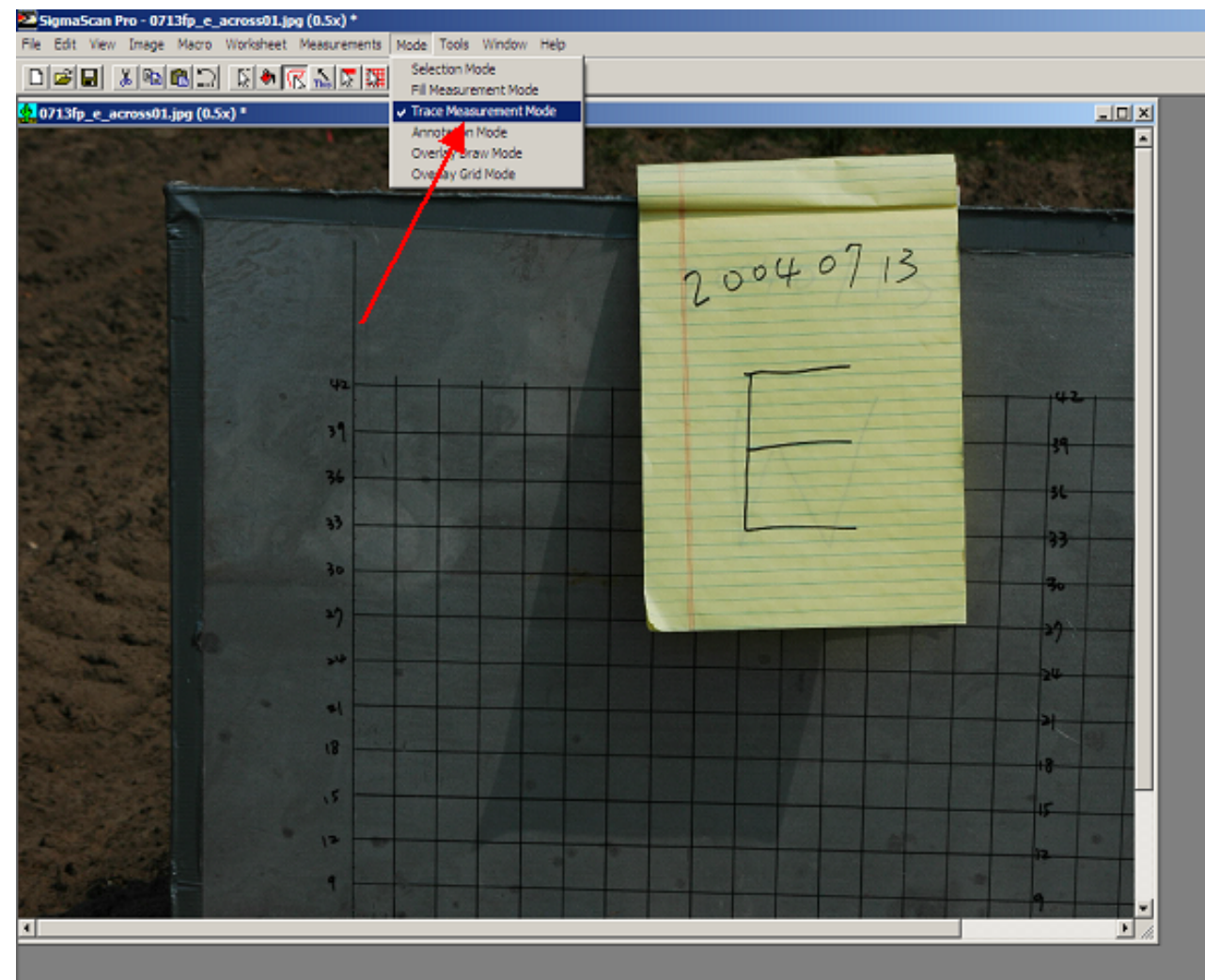


7) Start from the left of the soil surface profile. The first point is where the soil surface intersects the grid at $(0, Y)$. Click on the point at the soil surface profile every $1 \mathrm{~cm}$ in the image to the last point possibly seen in the image (The grid board of the example is 3 by $3 \mathrm{~cm}$, e.g. 2 points between the grids). Note that a worksheet will pop up once the first point is selected.

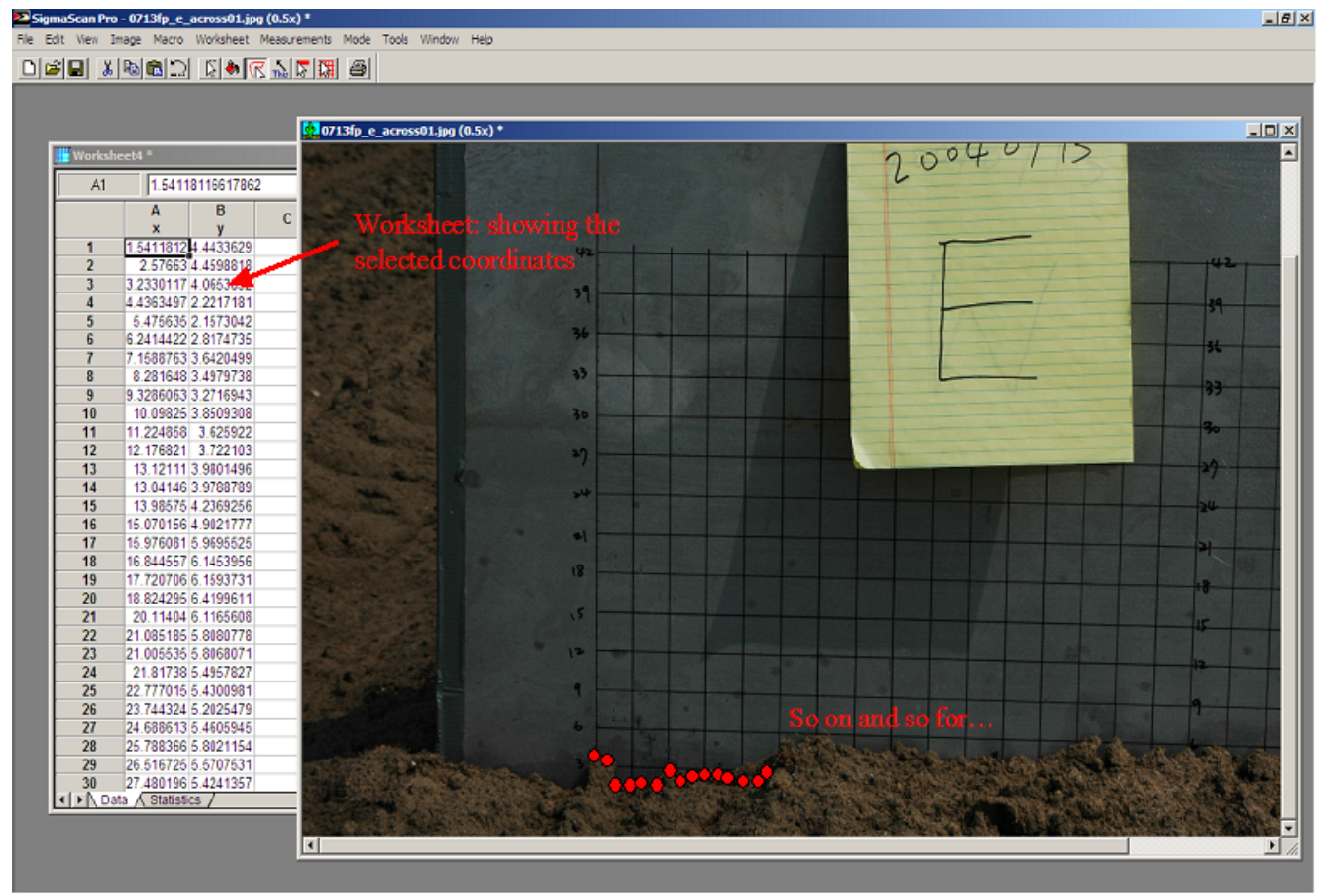

8) Click on the worksheet once the last point is selected. Then select File>Save, to save the coordinates into an Excel file and close SigmaScan.

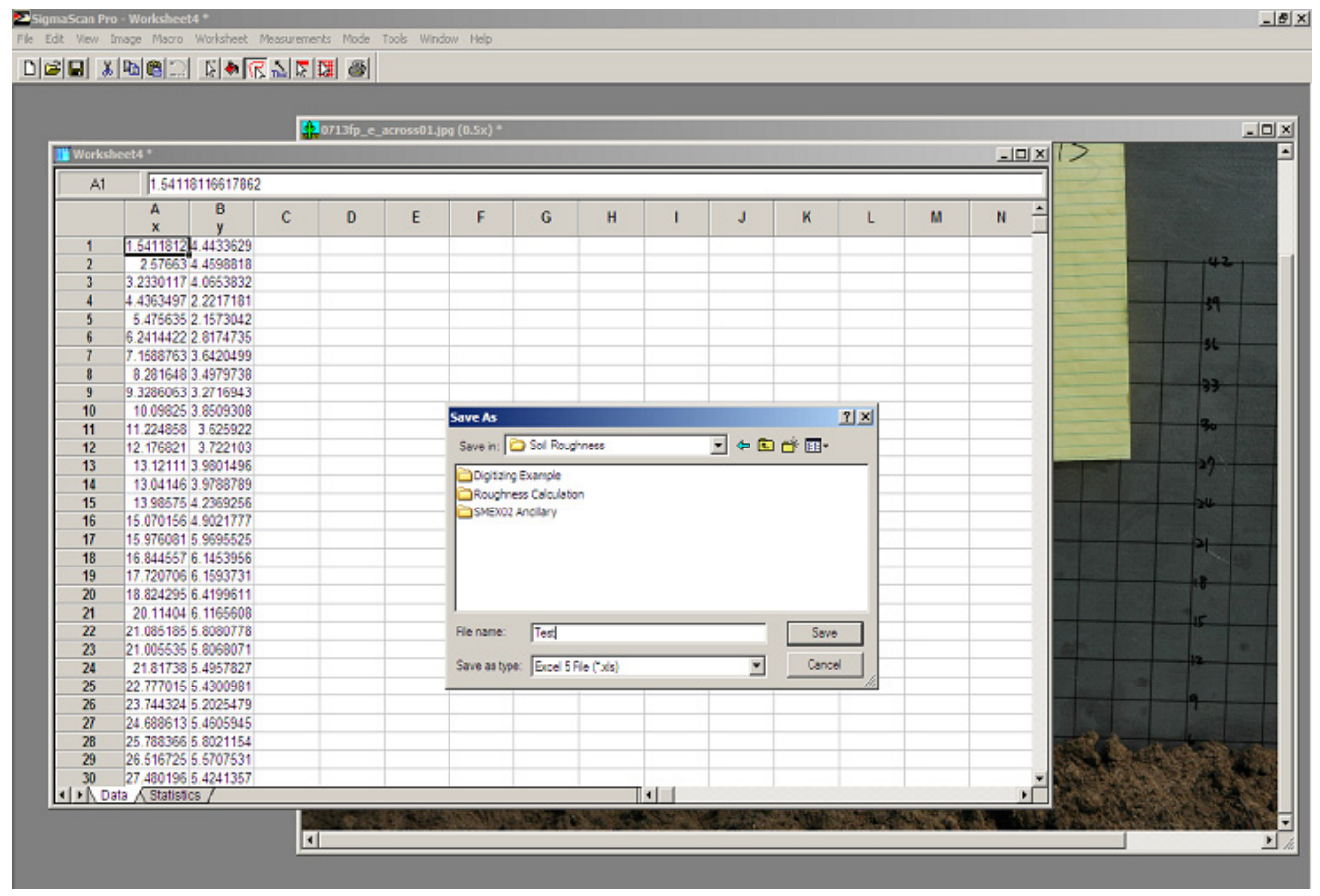




\section{B. EXCEL Spreadsheet for Roughness Calculations}

1) Open the EXCEL file Surface_Roughness_Calc.xls. Enable Marcos.

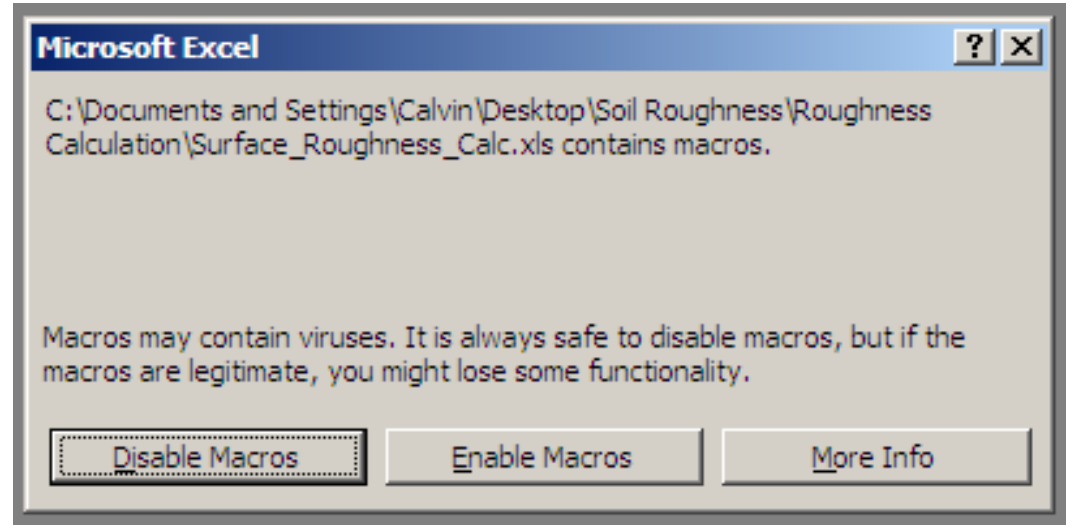

2) Open the digitize soil surface profile saved by the Sigmascan and copy the Column A and B to the Column A and B in the Surface_Roughness_Calc.xls.

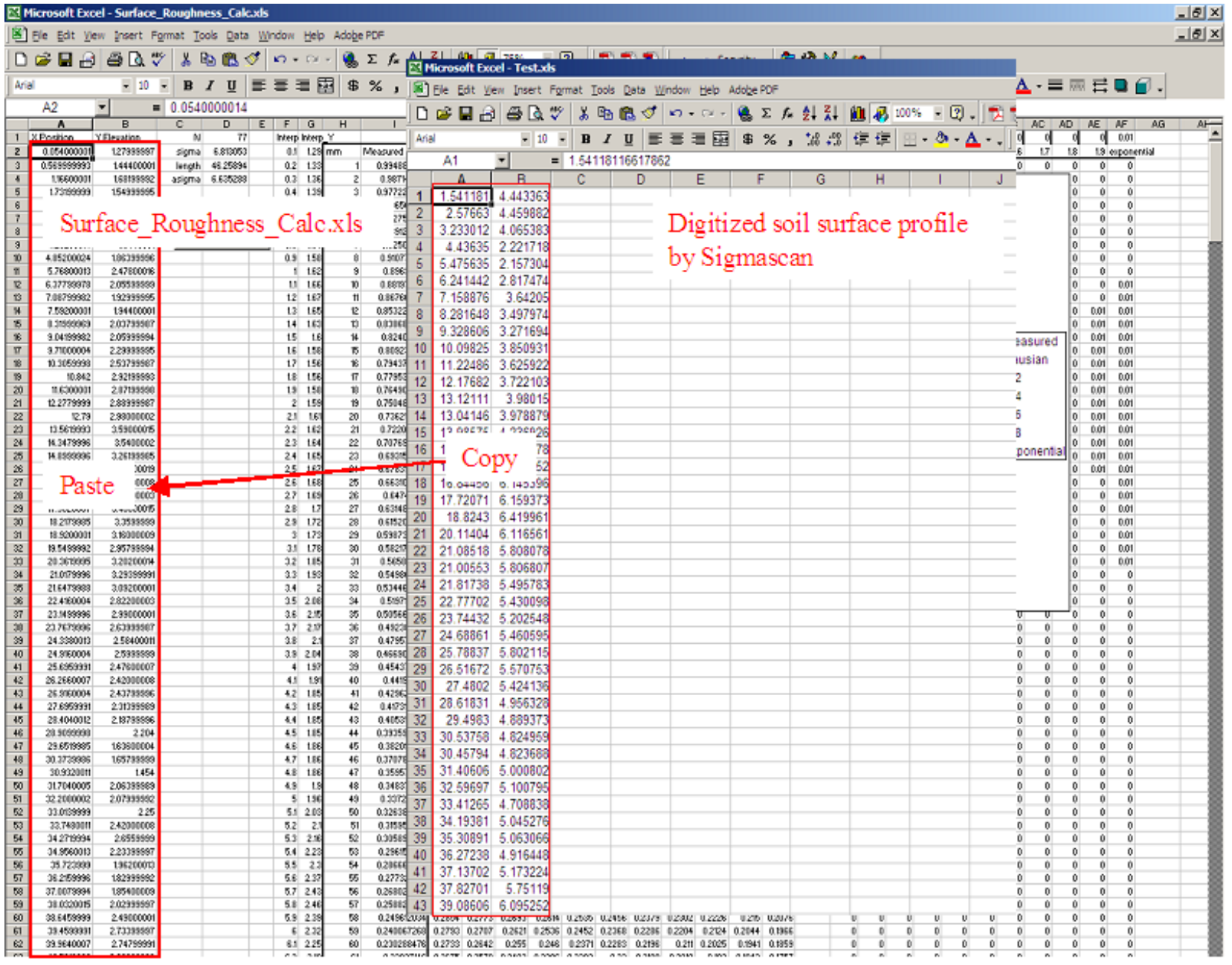


3) Click "compute roughness" to calculate the roughness parameters. The number of sampling points is shown in Column D Row 1. The root mean square height $(\sigma)$, autocorrelation length $(l)$, and slopecorrected root mean square height $\left(\sigma_{a d j}\right)$ are listed in Column D Row 2, 3, and 4, respectively.

\begin{tabular}{|c|c|c|c|c|c|c|c|c|c|c|}
\hline \multicolumn{11}{|c|}{ Microsoft Excel - Surface_Roughness_Calcxks } \\
\hline \multicolumn{11}{|c|}{ 짐 Ele Edit View Insert Format Iools Data Window Help Adobe PDF } \\
\hline \multicolumn{2}{|c|}{ 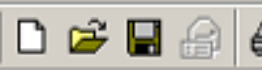 } & 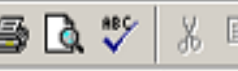 & 晋果 & $n+\infty x+1$ & 8 & $\Sigma$ & $f_{\text {t: }} \mathrm{A} \downarrow$ & Z $\downarrow$ & (1) & $100 \% \cdot$ \\
\hline \multicolumn{2}{|c|}{ Arial } & $\cdot 10 \cdot \mathrm{B}$ & $\underline{\mathrm{U}}$ & 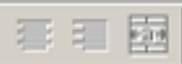 & \$ & B $\%$ & , 700 & $9 ; 00$ & & 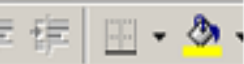 \\
\hline \multicolumn{11}{|c|}{$=1.54118116617862$} \\
\hline & $\mathrm{A}$ & \begin{tabular}{c|}
$\mathrm{B}$ \\
\end{tabular} & $\mathrm{C}$ & D & $E$ & $\mathrm{~F}$ & $G$ & $\mathrm{H}$ & & 1 \\
\hline 1 & X Position & Y Elevation & $\mathrm{N}$ & 60 & & Interp & Interp. & $\mathrm{Y}$ & & \\
\hline 2 & 1.541181166 & 4.443362915 & sigma & 11.76604 & & 0.1 & 1.29 & $\mathrm{~mm}$ & & Measured \\
\hline 3 & 2.576629999 & 4.45988181 & length & 58.32995 & & 0.2 & 1.33 & & 1 & 0.983828631 \\
\hline 4 & 3.233011725 & 4.065383221 & asigma & 10.45178 & & 0.3 & 1.36 & & 2 & 0.966353868 \\
\hline 5 & 4.436349715 & 2.221718112 & \multirow{5}{*}{\multicolumn{3}{|c|}{ compute roughness }} & 0.4 & 1.39 & & 3 & 0.947745284 \\
\hline 6 & 5.475635037 & 2.157304194 & & & & 0.5 & 1.42 & & 4 & 0.92817245 \\
\hline 7 & 6.241442227 & 2.817473538 & & & & 0.6 & 1.46 & & 5 & 0.907643232 \\
\hline 8 & 7.158876259 & 3.642049874 & & & & 0.7 & 1.5 & & 6 & 0.886254742 \\
\hline 9 & 8.28164798 & 3.497973829 & & & & 0.8 & 1.54 & & 7 & 0.864202952 \\
\hline 10 & 9.328606279 & 3.271694286 & & & & 0.9 & 1.58 & & 8 & 0.841653515 \\
\hline 11 & 10.09824996 & 3.850930817 & & & & 1 & 1.62 & & 9 & 0.818742961 \\
\hline 12 & 11.22485817 & 3.625921959 & & & & 1.1 & 1.66 & & 10 & 0.79559521 \\
\hline 13 & 12.1768206 & 3.722102982 & & & & 1.2 & 1.67 & & 11 & 0.772253533 \\
\hline 14 & 13.12111006 & 3.980149631 & & & & 1.3 & 1.65 & & 12 & 0.748980205 \\
\hline 15 & 13.04146015 & 3.978878947 & & & & 1.4 & 1.63 & & 13 & 0.725628853 \\
\hline 16 & 13.9857496 & 4.236925596 & & & & 1.5 & 1.6 & & 14 & 0.702249695 \\
\hline 17 & 15.07015643 & 4.902177676 & & & & 1.6 & 4.44 & & 15 & 0.678892724 \\
\hline 18 & 15.976081 & 5.96955245 & & & & 1.7 & 4.45 & & 16 & 0.669966696 \\
\hline 19 & 16.84455703 & 6.145395602 & & & & 1.8 & 4.45 & & 17 & 0.661429813 \\
\hline 20 & 17.72070604 & 6.159373129 & & & & 1.9 & 4.45 & & 18 & 0.653571057 \\
\hline
\end{tabular}


4) There are two methods to determine the power coefficient. The first method is to interpret it from the distance vs. autocorrelation plot. The bold red curve is the measurement. Choose the closet curve to the measured curve. The second method is to observe the values in Columns $\mathrm{J}$ through $\mathrm{T}$ and Rows 1 and 2. The values in Columns $\mathrm{J}$ through $\mathrm{T}$ in Row 1 are the measurements. The values in Columns $\mathrm{J}$ through $\mathrm{T}$ in Row 2 are the theoretically derived values. If the measurement curve fits between the Gaussian and Exponential distributions, one of the measurement values will be equal to zero (i.e. one of the values in Columns $\mathrm{T}$ through $\mathrm{J}$ in Row 1 will be zero). Otherwise, choose the closest distribution. For example, the following figure shows the measurement curve is not within the range of Gaussian and Exponential. However, the decrease in measurement values is closer to Gaussian instead of Exponential. In this case, the power coefficient $(n)$ (see equation 7 ) will be 1.5 .

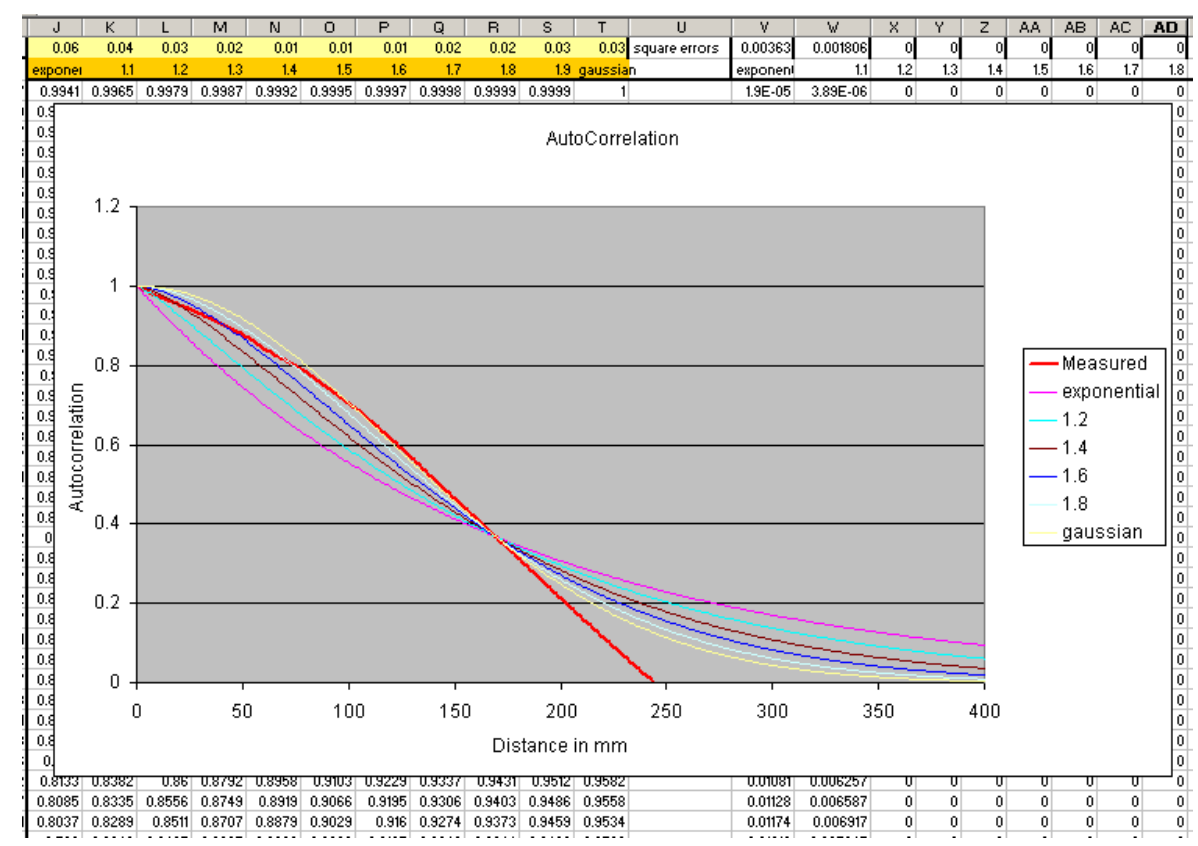

5) Open a blank Excel spread sheet. In the first row, type in File Name, Num of Pts, Sigma, L, Sigma Adj, and $\mathrm{n}$ in Column A, B, C, D, E, and F respectively. The File Name will be the name of the raw roughness image. Fill in the values calculated by Surface_Roughness_Calc.xls in the corresponding spaces.

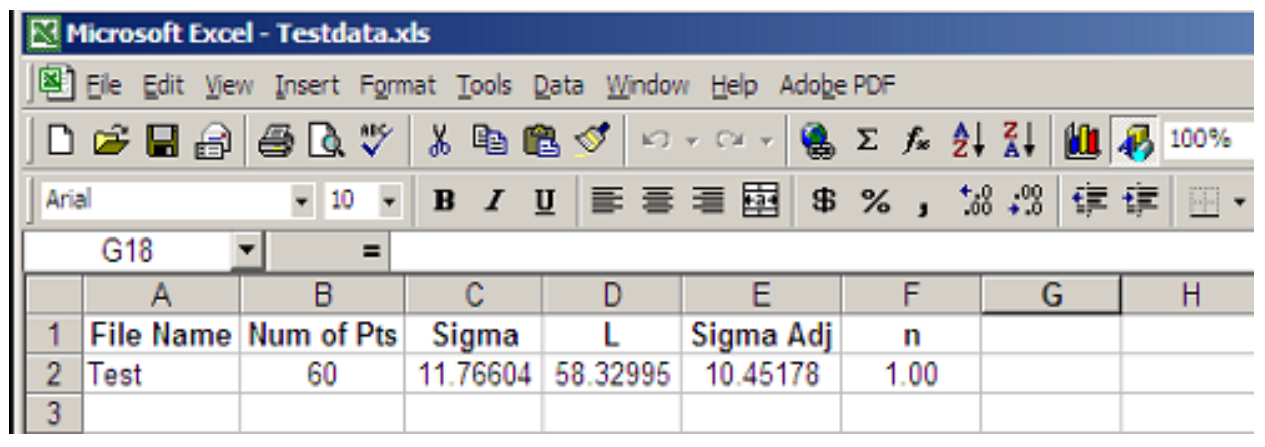

